\title{
Mechanisms of Neuroprotection Underlying Physical Exercise in Ischemia - Reperfusion Injury
}

\author{
David Dornbos III and Yuchuan Ding \\ Wayne State University Department of Neurological Surgery
}

USA

\section{Introduction}

Cerebrovascular accidents carry significant morbidity and mortality and are vastly present in current society. One of the most prevalent causes of death and long-term disability within the United States, stroke was found to directly cause 6 million deaths in 2006 and was found to be indirectly attributed to $\$ 73.7$ billion in health care costs in 2010 (Lloyd-Jones et al., 2010). Current standard of care requires that patients present to a health care facility very early in disease onset so thrombolytic therapy can be initiated; however, this therapy, focusing on the establishment of reperfusion is not ideal as reperfusion often worsens ischemic injury (Yang and Betz, 1994). Clearly, new therapeutic and pharmacologic interventions are needed.

Exercise has long been known to provide protection for ischemic stroke through the amelioration of stroke risk factors. Through its beneficial effects on hypertension, lipid profiles, obesity, and diabetes, exercise training has been associated with decreased stroke incidence and better outcomes after stroke (Evenson et al., 1999; Gillum et al., 1996; Hu et al., 2004). Despite risk factor management, exercise has also been shown to provide endogenous neuroprotection, preserving neuronal viability in the setting of ischemia/ reperfusion injury, resulting in decreased infarct volume and improved neurologic recovery (Chaudhry et al., 2010; Curry et al., 2009; Davis et al., 2007; Ding et al., 2004a, 2004b, 2005, 2006a, 2006b; Guo et al., 2008a; Liebelt et al., 2010; Zwagerman et al., 2010a, 2010b). These beneficial endogenous effects of exercise preconditioning have been seen even after multivariate analysis has controlled for risk factor alterations (Hu et al., 2005).

Multiple studies have shown the endogenous protection of rat myocardium following exercise preconditioning (Powers et al., 2002; Siu et al., 2004) through attenuation of apoptosis and better outcomes following reperfusion. Similarly, endogenous neuroprotection has been shown to take place through multiple mechanisms, including upregulation of neurotrophin expression, strengthening of the blood brain barrier (BBB), enhancing the cerebral capillary and arterial networks, decreasing inflammation and apoptosis, and improving cerebral metabolism. Through these mechanisms, exercise preconditioning provides valuable insight into the science of endogenous neuroprotection and its potential therapeutic and clinical implications. 


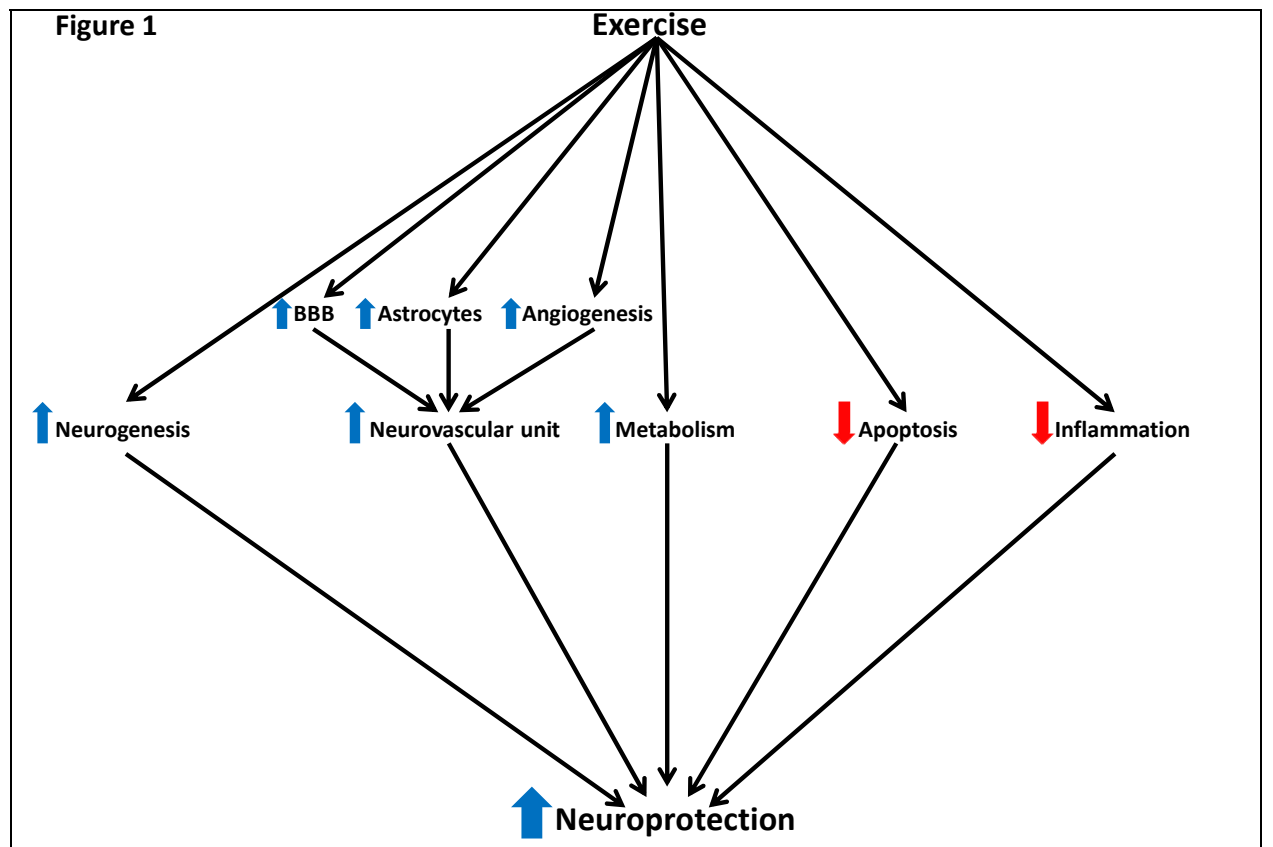

Fig. 1. Exercise generates endogenous neuroprotection through the development of neurogenesis, improved integrity of the neurovascular unit, enhanced metabolism, decreased apoptosis, and amelioration of inflammation.

\section{Methods of preconditioning}

To date, no specific guidelines have been established through human studies to convey adequate or optimal neuroprotection. Although exercise has been shown to convey endogenous neuroprotection and innate cardioprotection (Hu et al., 2004; Kloner, 2001), the extent, duration, and type of exercise has not been conclusively studied. Despite this, a previous study revealed that moderate intensity and duration of exercise, as opposed to mild or strenuous, correlates with better outcomes and life improvements (Larson et al., 2006). There are specific exercise modalities which convey more potent neuroprotection, and exercise of any duration appears to be neuroprotective. Certainly more studies, especially with human subjects, need to be performed in order to determine exercise regimens resulting in maximal neuroprotection.

\subsection{Duration of preconditioning}

Despite its known neuroprotective effects, no specific duration of exercise has been shown to provide maximal neuronal survival or lead to better neurologic outcomes. Through multiple studies in rats, it can be seen that exercise preconditioning prior to ischemia/reperfusion injury for a duration of as little as 2 weeks and up to 12 weeks provides similar levels of neuroprotection (Ang et al., 2003; Curry et al., 2009; Davis et al., 2007; Ding et al., 2004a; Stummer et al., 1994; Wang et al., 2001). In addition to the duration of exercise needed, another important factor revolves around the extent of 
neuroprotection after exercise has stopped. Another study revealed that the neuroprotective effects of exercise preconditioning appear to be long-lasting, showing that 3 weeks after cessation of exercise, rats still maintained lower levels of neurologic deficit and decreased stroke volume when compared to non-exercise rats (Ding et al., 2004b). Future human studies ought to determine the exact duration needed for maximal endogenous neuroprotection.

\subsection{Preconditioning modalities}

While various modalities, such as treadmill running, voluntary running, simple and complex exercise, have been shown to provide variable amounts of neuroprotection. When comparing forced exercise on a treadmill to voluntary running on a running wheel, rats forced to exercise on a treadmill tend to have better neurologic outcomes after stroke (Hayes et al., 2008). Previous studies have shown that forced exercise on a treadmill is slower but more constant than voluntary exercise occurs in shorter spurts with faster speed, although the total distance is equal in the two groups (Noble et al., 1999). This neuroprotection in forced exercise subjects led to decreased stroke volume, lessened neurologic deficit, upregulation of heat shock proteins, increased neurogenesis and cerebral metabolism (Hayes et al., 2008; Kinni et al., 2011; Leasure and Jones, 2008). These findings show that moderate exercise over a longer time period conveys more efficient and greater neuroprotection than more vigorous exercise over shorter time periods.

In addition to the studies assessing forced and voluntary exercise, differences have also been established when comparing simple and complex exercise. This study analyzed simple exercise as the repetitive movements of treadmill running, whereas complex exercise constituted enriched activities which required both balance and coordination (Ding et al., 2003). Following ischemia/reperfusion injury, rats preconditioned with complex exercise demonstrated increased synaptogenesis and improved neurologic outcomes when compared to simple treadmill exercise (Ding et al., 2003; Jones et al., 1999). Simple exercise training also alleviates much of the injury following ischemia/reperfusion, but its benefit is less pronounced than what is observed with complex exercise training. Although no human studies have definitively shown the most effective means of exercise for enhanced neuroprotection, these animal studies provide a solid framework for the development of appropriate exercise regimens. Moderate exercise intensity, including components of balance, coordination and stress, taking place over a sustained duration seem to be the most neuroprotective when compared to other exercise modalities and intensities.

\section{Mechanisms of neuroprotection}

Exercise clearly provides substantial endogenous neuroprotection in addition to its role in risk factor reduction for ischemia/reperfusion injury. These effects have been shown through a wide variety of neuroprotective mechanisms all which increase neuronal survival in the setting of ischemic stroke. These protective effects revolve around the neurovascular unit, composed of neuronal, glial, and vascular cells. This unit is significantly enhanced through exercise training and is injured through ischemia/reperfusion. As such, its integrity is paramount for proper cerebral functioning and is the focal point of the neuroprotective effects of exercise in ameliorating ischemic injury. This neuroprotection is, in part, conveyed through the upregulation of neurotrophin expression, including brain derived neurotrophic factor (BDNF) and nerve growth factor (NGF). These important regulatory proteins increase 
neurogenesis, providing a richer neuronal network prior to injury and a more potent neuronal regenerative ability.

In addition to enhanced neurogenesis, exercise neuroprotection also serves to enhance neurovascular unit integrity through strengthening of the blood brain barrier (BBB). Exercise has been shown to enhance the expression of basal lamina proteins and to increase astrocytosis, effectively providing greater stability to the BBB and the neurovascular unit. Matrix metalloproteinases have also been shown to be downregulated following exercise, enzymes which normally degrade the BBB. Furthermore, angiogenic factors, such as vascular endothelial growth factor (VEGF) and angiopoietins (Ang1 and Ang 2), are upregulated following exercise and correlated with increased blood vessel density and increased cerebral blood flow (CBF). These changes provide further stability to the neurovascular unit and have been shown to provide better outcomes following ischemia/reperfusion injury.

Exercise also regulates apoptotic pathways in such a way as to tip the balance in favor of anti-apoptotic to pro-apoptotic gene expression. Carried out through mediators, such as tumor necrosis factor (TNF)- $\alpha$, extracellular regulated kinase (ERK)-1/2, and heat shock protein (HSP)-70, increasing the anti:pro-apoptotic ratio effectively decrease apoptosis and prolongs neuronal survival, providing obvious benefit following ischemia/reperfusion injury. Furthermore, exercise preconditioning decreases the expression of vascular adhesion molecules (ICAM-1), which decreases leukocyte infiltration and secondary damage following ischemic stroke. These changes ameliorate much of the neuronal damage and death after hypoxic conditions. Finally, neuronal metabolism is upregulated following chronic exercise, correlating with increased ATP production in the acute phase following ischemia/reperfusion injury. This is done through upregulation of glucose transport enzymes, glycolytic enzymes, and the upstream regulator protein hypoxia-inducible factor (HIF)-1 $\alpha$. The pathways underlying these mechanistic changes in response to exercise preconditioning will be defined in detail as each provides valuable clues to understanding the protective ability of exercise following ischemia/reperfusion injury.

\subsection{Neurotrophin expression}

Neurotrophins are well known to enhance neurogenesis and synaptogenesis while working to promote cerebral integrity at its most basic unit. Multiple human and animal studies have revealed that brain derived neurotrophic factor (BDNF) and nerve growth factor (NGF) facilitate this process (Cohen-Cory et al., 2010; Kim et al., 2004; Kuipers and Bramham, 2006). These trophic factors generate more abundant neuronal and synaptic networks, and they have also been shown to be protective of the neural and cerebrovascular systems. BDNF and NGF mRNA levels have been shown to be upregulated following several weeks of continuous exercise (Ding et al., 2004b), which has been specifically seen in astrocytes and neuronal cells. In addition, providing exercise in an enriched environment, including running wheels, toy balls, ladders, and wooden planks, increased synaptogenesis and neurologic functioning even more than previously seen with basic exercise preconditioning, which was also associated with an increase in BDNF and NGF mRNA levels (Neeper et al., 1996; Ickes et al., 2000). This further implies that complex exercise, requiring balance and coordination, transmits greater neuroprotection that basic repetitive exercise.

Upregulation of these proteins following chronic exercise generates increased neurogenesis, which is protective in advance of ischemia/reperfusion injury. Several studies have shown 
that exercise preconditioned rats have elevated levels of BDNF and NGF following ischemia/reperfusion injury, which correlates with decreased neurologic deficit and decreased stroke volume when compared to non-exercised rats (Ang et al., 2003; Ding et al., 2004a). Another study has shown these factors to be upregulated within the reperfusion stage as well (Schabitz et al., 2007), suggesting a possible reparative role post-ischemic insult. The ability to upregulate these neurogenic factors in the reperfusion stage provides the potential for cell survival and regeneration, especially within the ischemic penumbra zone. These results suggest a temporally duel role of BDNF and NGF in exercise preconditioning in which their upregulation via chronic exercise training strengthens the neurovascular unit before and after injury. Altogether, the upregulation of BDNF and NGF seen following exercise preconditioning promotes neuronal survival following ischemia/reperfusion injury.

\subsection{Integrity of the neurovascular unit}

In addition to neuronal health and viability, integrity of the neurovascular unit as a whole requires maintenance of the blood brain barrier (BBB), structural support provided by astrocytic glial cells, and an intact cerebrovascular network. Composed of capillary endothelial cells, the basal lamina, and astrocytic end-feet, the BBB provides a robust filtration mechanism which serves as the functional barrier for neurovascular unit integrity in the setting of ischemic stroke. Also the first structure injured after ischemia/reperfusion injury, the strength of the BBB is of utmost importance and is a key component to the neuroprotection afforded by exercise training.

While viewing the neurovascular unit as the most basic structure for neuroprotection and stability, astrocytes also play a key role in maintaining the cerebral architecture. Seen following chronic exercise, astrocytosis strengthens the BBB and neurovascular unit, providing a rigid framework to withstand ischemia/reperfusion insults against the neurovascular unit.

Not only does exercise promote neuronal health, BBB integrity, and astrocytic structure, but it also generates an increased blood vessel density. Increased collateral circulation coupled with richer capillary beds allows a more efficient and effective response to ischemia. The angiogenesis and arteriogenesis seen after exercise allow the brain to be rapidly reperfused. In exercised subjects with enhanced BBB integrity, this elevated reperfusion potential occurs much more proficiently and with less damage than is seen in non-exercised subjects. These neuroprotective changes in exercised animals in the setting of ischemia/reperfusion injury underlie the importance of pre-ischemic exercise conditioning and provide potential novel therapeutic interventions.

\subsubsection{Blood Brain Barrier integrity}

The integrity of the blood brain barrier (BBB) is paramount to maintaining proper filtration of nutrients from the vascular system and in providing the necessary structure to the neurovascular unit. Composed of endothelial cell walls, the basal lamina, and astrocytic end-feet, this filtration barrier is the first structure injured during ischemia/reperfusion injury (del Zoppo and Hallenbeck, 2000; del Zoppo and Mabuchi, 2003), making its integrity a key focal point in the neuroprotective nature of exercise. While an intact endothelial cell wall and astrocytic end-feet are necessary for proper BBB functionality, the basal lamina provides the central structural support and selective permeability necessary to maintain a 
healthy cerebral environment. The basal lamina is composed of various proteins of the extracellular matrix, including collagen type IV, laminin, heparan sulphate, proteoglycan, and fibronectin, which are produced by surrounding endothelial cells and astrocytes. The importance for proper integrity and functionality of this structure has been repeatedly established (Lo et al., 2003, Lo et al., 2005). When this barrier is damaged, as is the case following ischemia/reperfusion injury, its ability to selectively discriminate products of the cerebrovascular system is compromised, which is clinically evident as vasogenic edema.

In a hypoxic setting, this loss of BBB integrity and introduction of cerebral edema further disturbs cerebral homeostasis in a step-wise manner. Soon after arterial occlusion, the endothelial permeability barrier is lost and matrix proteins, primarily fibronectin, collagen, and laminin, also begin to lose their integrity (del Zoppo and Mabuchi, 2003). As ischemia continues, a lack of selective permeability and continued vasogenic edema lead to cellular swelling. Swelling of astrocytes and endothelial cells separates them further from the basal lamina, further promoting leakage of vascular contents into the cerebral interstitial spaces (del Zoppo and Mabuchi, 2003). Reperfusion tends to worsen this damage, despite its role as the current mainstay of therapy for ischemic stroke. These alterations in the ischemic phase severely damage the integrity of the $\mathrm{BBB}$, and the sudden increase in cerebrovascular flow in the reperfusion stage leads to excessive leakage of water and generation of oxygen free radicals, further promoting cerebral damage (Ayata and Ropper, 2002; Yang and Betz, 1994). Studies have shown that exercise training increases basal lamina thickness, adding both strength and stability to the BBB (Davis et al., 2007). These changes were associated with decreases cerebral edema, decreased stroke volume, and improved neuronal recovery following ischemia/reperfusion injury. Collage type IV, a major component of the basal lamina, was found to be upregulated in exercise preconditioned rats, and these subjects maintained a decreased net loss of collagen type IV levels after stroke as well (Davis et al., 2007). Also confirmed by immunocytochemistry, elevated levels of collagen type IV-positive cells were observed in previously exercise rats, and these rats had significantly lower levels of neurologic deficit following stroke (Davis et al., 2007).

In a similar manner to collagen expression, integrin proteins also provide stability to the basal lamina and BBB, providing additional support to the neurovascular unit. Composed of $\alpha$ and $\beta$ heterodimers, these proteins serve as cell adhesion molecules within the basal lamina and extracellular matrix, anchoring astrocytes and endothelial cells together, ultimately maintaining the integrity of these structures and the neurovascular unit as a whole (Dans and Giancotti, 1999; Hynes, 1992). Integrins, which are anchored to astrocytic and endothelial cytoskeletons, serve as receptors for numerous ligands and proteins within the basal lamina matrix, primarily collagen and laminin (del Zoppo and Mabuchi, 2003; Tawil et al., 1994). These structural proteins also serve as signalling receptors for astrocytes and endothelial cells, allowing for dynamic alterations of the BBB in response to exercise, ischemia, and other noxious stimuli (Hynes, 1992). Following ischemic/reperfusion injury, these proteins rapidly lose affinity for their associated ligands within the basal lamina, decreasing the connective integrity between endothelial and astrocytic cells and the extracellular matrix (Tagaya et al., 2001; Wagner et al., 1997). However, in exercised-trained rats, integrin expression was found to be significantly higher in astroglia and endothelium following ischemic stroke (Ding et al., 2005; Tawil et al., 1994), which correlated with a decrease in neurologic deficit (Ding et al., 2006b). These changes suggest that integrin expression is uniquely important to BBB integrity as it serves to bind all three components 
together, and this increased expression following exercise serves as another mechanism of its neuroprotective nature. Through both increased collagen and integrin expression following exercise preconditioning, the enhanced integrity of the BBB decreases vasogenic edema, secondary damage, and neuronal death following ischemia/reperfusion.

While it can clearly be seen that exercise increases the thickness and integrity of the basal lamina and $\mathrm{BBB}$ as a whole, pre-ischemic exercise also improves integrity of the neurovascular unit by decreasing BBB breakdown. Matrix metalloproteinase (MMP) is an enzyme produced by endothelial cells, microglia, and astrocytes with a primary function to degrade extracellular matrix and basal lamina proteins (Lo et al., 2003). Expression of MMPs increases exponentially following cerebral damage and, as a result, has been heavily implicated following ischemia/reperfusion injury (Lo et al., 2003). Upregulation of MMP following stroke has been implicated in multiple animal and human studies (Clark et al., 1997; Gasche et al., 1999), leading to increased BBB permeability and vasogenic edema. In addition to these damaging changes, MMP expression has also been correlated with increased inflammation and leukocyte infiltration (Romanic et al., 1998). Pharmacologic inhibition (Romanic et al., 1998) and genetic knockout (Asahi et al., 2001) of MMPs leads to a dramatic decrease in associated edema and neurologic damage. MMP-induced damage following ischemia/reperfusion is mechanistically linked to extracellular matrix breakdown, including degradation of collagen, leading to loss of integrity of the BBB and the neurovascular unit.

Following exercise preconditioning, rats were found to have reduced MMP-9 expression, which correlated with elevated collagen IV levels (Davis et al., 2007), and similar results were seen following pharmacologic inhibition. This neuroprotective effect of exercise is mediated by improved microvascular integrity and basal lamina reinforcement, ultimately decreasing neurologic deficit, infarct volume, and leukocyte infiltration following ischemia/reperfusiom injury (Curry et al., 2009). Interestingly, when these same rats were treated with tumor necrosis factor (TNF)- $\alpha$ antibody or inhibition of extracellular regulated kinase (ERK), MMP-9 levels were not decreased, and the positive effects on neurologic outcome and infarct volume were no longer seen (Curry et al., 2009; Hosomi et al., 2005), suggesting that TNF- $\alpha$ and ERK serve as regulators of MMP expression. Further studies have shown that ERK1/2 mediates a TNF- $\alpha$ induced an increase in MMP-9 expression in the acute setting (Arai et al., 2003), while the gradual increases in TNF- $\alpha$ and ERK1/ 2 have been shown to decrease MMP-9 expression and lead to decreased neuronal cell death (Chaudhry et al., 2010). These gradual changes are seen following exercise training, in which gradual upregulation of TNF- $\alpha$ and ERK1/2 lead to decreased levels of MMP-9 expression, which also correlates with better outcomes following ischemia/reperfusion injury (Chaudhry et al., 2010). In this study, following ischemic injury, neuronal apoptosis was seen to be reduced in association with decreased levels of MMP-9 expression in exercise preconditioned rats (Chaudhry et al., 2010). Following pharmacologic inhibition of both ERK1/2 and MMP-9, similar effects were also seen, resulting in less neuronal apoptosis and better neurologic outcomes; however, when only ERK1/2 was inhibited, MMP expression returned to the level of non-exercised control rats, suggesting a pathway involving regulation by ERK1/2 and TNF- $\alpha$ of MMP-9 expression (Chaudhry et al., 2010). ERK1/2 has previously been shown to also work through upregulation of tissue inhibitors of metalloproteinases (TIMPs) (Tong et al., 2004), and TIMPs have been previously shown to be upregulated following chronic exercise in association with decreased MMP-9 levels (Guo et al., 2008a). The 
upregulation of ERK1/2 and TNF- $\alpha$ following exercise preconditioning, leads to decreased MMP-9 expression, decreased BBB dysfunction, improved neurovascular unit integrity, and better neurologic outcomes. In addition to these important findings regarding the role of ERK1/2 and TNF- $\alpha$, heat shock proteins (HSP-70) are also thought to play a synergistic role in the downregulation of MMP-9 expression (Liebelt et al., 2010). HSP-70 works in concert with TNF- $\alpha$ to decreased MMP-9 expression and has been shown to be increased following chronic exercise training. Taken together, these various pathways reveal multiple synergistic pathways which function to reduce the breakdown of the $\mathrm{BBB}$, reinforcing the integrity of the neurovascular unit and the cerebral environment.

\subsubsection{Astrocytosis}

Another vital player in the neurovascular unit is the astrocyte, which also forms the cerebral side of the blood brain barrier (BBB). Astrocytic glial cells are well known to induce strengthening of the BBB (Park et al., 2003; Petty and Lo, 2002). Specifically, these cells have been shown to cover $90 \%$ of the cerebrovascular surface and primary function to restrict the permeability across the BBB, providing crucial integrity to the neurovascular unit (Igarashi et al., 1999; Janzer and Raff, 1987; Kondo et al., 1996; Willis et al., 2004). The density and integrity of astrocytes within the brain have also been shown to maintain neurovascular integrity in the setting of acute ischemic stroke (del Zoppo and Mabuchi, 2003; Lo et al., 2005). The damaging effects of ischemia/reperfusion are primarily seen at the BBB, classically affecting endothelial cells and astrocytes and their corresponding adherence to the extracellular matrix. This interaction between endothelial cells, the extracellular matrix, and astrocytes provides the central trigger for neuronal injury and death in the setting acute stroke (Petty and Wettstein, 2001). In addition to its other effects, pre-ischemic exercise conditioning has been shown to upregulate the degree of astrocytosis, and this upregulation has been shown to be correlated with better outcomes following ischemic/reperfusion injury ( $\mathrm{Li}$ et al., 2005). An increased number of astrocytes within the neurovascular unit, provided by exercise training, cover a greater percentage of the BBB. This increased coverage allows the neurovasculature to be more restricted in the blood products that are allowed to permeate the BBB, providing important integrity in the setting of ischemia/reperfusion injury.

\subsubsection{Angiogenesis and arteriogenesis}

Exercise training transforms the neurovascular system of the neurovascular unit, developing a vital metabolic response network in response to ischemia/reperfusion injury. Under normal conditions, angiogenesis and endothelial cell proliferation is scant in the adult brain (Ogunshola et al., 2000). Nonetheless, as a major element of the neurovascular unit, it plays a crucial role in maintaining an appropriate and healthy cerebral environment. Previous studies have shown that physical activity on a treadmill increases blood vessel density in the brain (Black et al., 1990; Isaacs et al., 1992; Kleim et al., 2002; Swain et al., 2003), and forced exercise on a treadmill induces cortical and striatal angiogenesis (Ding et al., 2004a, 2004b). In addition to these increases in angiogenesis, exercise preconditioning also increases arteriogenesis, which promotes cerebral blood flow (CBF), increases collateral circulation, and ameliorates neuronal injury and death following ischemia/reperfusion injury (Lloyd et al., 2003, 2005). Closely linked to the metabolic requirements needed by the brain during levels of high activity, the amount of blood supply provides the necessary avenue to 
produce the needed glucose and oxygen. Through increasing this metabolic demand, exercise leads to permanent structural alterations, such as angiogenesis and arteriogenesis, and these changes allow the increased delivery of vital nutrients to active neurons (Isaacs et al., 1992; Vissing et al., 1996). These structural changes not only facilitate increased glucose and oxygen delivery, but they have also been shown to reduce brain damage as well (Ding et al., 2004a).

The structural alterations seen with angiogenesis are driven by several regulator proteins, namely vascular endothelial growth factor (VEGF) and angiopoietins (Ang) 1 and 2. VEGF and Ang1/2 are known to be expressed in greater abundance following exercise training, and these changes lead to increased blood vessel density (Ding et al., 2004b). Expression of Ang 1 and 2 mRNA has been shown to be increased as early as 1 week after the onset of exercise training (Ding et al., 2006b), and VEGF mRNA expression has been shown to be mildly increased at 1 week but exponentially higher after 3 weeks of exercise training (Matsumori et al., 2005; Nawashiro et al., 1997; Sawatzky et al., 2006; Yong et al., 2001). Exercise-induced angiogenesis was also seen in aging rats with associated increases in VEGF and Ang1/2 mRNA levels (Ding et al., 2006b), suggesting that angiogenesis can be expected in the adult brain. Although most proliferation of the neurovascular system occurs during cerebral development, these findings reveal that VEGF and Ang1/2 drive this process in aging brains as well, further promoting the endogenous neuroprotection afforded by exercise preconditioning.

These changes occurring after chronic exercise also lead to better outcomes following ischemia/reperfusion injury. In addition to correlating with increased cerebral blood flow and glucose utilization, the angiogenesis and arteriogenesis observed following exercise preconditioning is associated with decreased neuronal cell death following ischemia/reperfusion injury ( $\mathrm{Li}$ et al., 2005). The process of angiogenesis provides considerably denser cerebrovascular networks, which bathes the brain in a network of vessels more apt to deliver the vital nutrients necessary for proper brain health and functioning. The additional benefit seen from arteriogenesis, following exercise preconditioning underscores the importance of increased collateral circulation, particularly vital in saving vital brain volume in the ischemic penumbra. Especially when coupled with astrocytosis, the angiogenesis seen following exercise preconditioning substantially contributes to the development and integrity of the $\mathrm{BBB}$, further promoting the neurovascular unit and protecting against ischemic/reperfusion injury.

\subsubsection{Cerebral blood flow and glucose uptake}

As previously discussed, exercise training increases angiogenesis and arteriogenesis, providing more avenues for potential blood delivery to the cerebral system. Previous studies with Laser Doppler flowmtery (LDF) and ${ }^{15} \mathrm{O}-\mathrm{H}_{2} \mathrm{O}$ positron emission tomography (PET) have shown that preischemic exercise preserves the cerebral blood flow (CBF) during the reperfusion stage in ischemia/reperfusion injury (Zwagerman et al., 2010b). Although CBF was similar in exercised and non-exercised groups during ischemia, CBF was significantly higher in the exercise preconditioned animals during reperfusion and was associated with a decreased volume of the infarct. This increase in perfusion during the reperfusion stage in preconditioned animals suggests that this training may partial ameliorate the "no reflow" phenomenon often seen following ischemia/reperfusion injury. 
In the same study, intracerebral glucose uptake was also assessed using an ${ }^{18} \mathrm{~F}$-fluorodeoxyD-glucose (FDG) radiotracer (Zwagerman et al., 2010b). Following ischemia/reperfusion injury, cerebral metabolism was significantly reduced as evidenced by a decrease in glucose uptake. However, in rats preconditioned with physical exercise, brain glucose uptake and metabolism was substantially preserved following reperfusion and was associated with a decrease in infarct volume and functional neurologic deficit. CBF and metabolism also increase during the act of physical exercise, signifying the increased metabolic demand on neuronal cells during training (Hellstrom et al., 1996; Ide and Secher, 2000; Vissing et al., 1996; Williamson et al., 1997) and the likely underlying mechanism through which neuroprotection is obtained. The angiogenic changes that occur following exercise preconditioning provide the brain with an enriched vascular bed with an enhanced ability for proper cerebral blood flow and glucose delivery to neurons, yielding more tolerance to reperfusion injury in the setting of ischemia/reperfusion.

\subsection{Inflammatory response}

The "no reflow" phenomenon refers to the tendency towards hypoperfusion during the reperfusion stage following ischemia. This hypoperfusion following transient ischemia is thought to stem from multiple mechanisms, including microvascular damage and cerebrovascular occlusion from cellular elements (Aspey et al., 1989; Dietrich et al., 1987; Mori et al., 1992; Nishigaya et al., 1991). In addition to these observed changes, hemoconcentration, red blood cell sludging, hyperviscosity, and platelet plugging tend to occur as well in the reperfusion phase, further exacerbating the damage seen in ischemia/reperfusion injury (Choudhri et al., 1998). While these effects of reperfusion injury causes significant damage, the accumulation of polymorphonuclear leukocytes are the primary contributors to the perfusion abnormalities observed following transient ischemia. The secondary inflammation after ischemia/reperfusion injury plays a major role in secondary brain damage through increased leukocyte infiltration, microvascular damage, and free radical accumulation during reperfusion.

\subsubsection{Adhesion molecules and toll-like receptors}

In the setting of ischemia/reperfusion injury, cytokines tend to stimulate the expression of cellular adhesion molecules, attracting leukocytes to the cerebrovascular system and promoting their diapedesis into the interstitial space. Two central cytokines in this process, interleukin-1 $\beta$ (IL-1 $\beta$ ) and tumor necrosis factor- $\alpha$ (TNF- $\alpha$ ), are known to be upregulated following periods of hypoxia and promote the expression of intercellular adhesion molecule 1 (ICAM-1), P-selectin, and E-selectin on leukocytes and endothelial cells. These changes lead to the leukocyte accumulation classically seen in ischemia/reperfusion, leading to adhesion of leukocytes to the damaged vascular endothelium, clogging of the neurovascular vessels, and infiltration into the brain parenchyma. Previous studies have shown that preischemic exercise training reduces the expression of ICAM-1, leading to decreased leukocyte infiltration and accumulation, in the reperfusion stage (Ding et al., 2005). This downregulation leads to decreased inflammation following ischemia/reperfusion injury and serves as another neuroprotective mechanism of exercise preconditioning.

Another mechanism underlying the inflammatory damage in the reperfusion stage pertains to the expression of toll-like receptors. These cell surface receptors are found within the brain and throughout the body and are actively involved in the immune response by 
binding endogenous and foreign materials and triggering a cytokine cascade (Gleeson et al., 2006). Previous research studies have also revealed that exercise preconditioning reduces the expression of Toll-like receptor-4 (McFarlin et al., 2006), and reduction of these receptors in Toll-like receptor-4 deficient mice has been shown to decrease tissue damage and neurologic deficits following ischemia/reperfusion injury (Cao et al., 2007). Another study looking at both of these factors has indicated that exercise preconditioning simultaneously reduces expression of Toll-like receptor-4, which leads to a reduction in brain injury following ischemic stroke (Zwagerman et al., 2010a).

\subsubsection{Leukocyte invasion}

Through the downregulation of adhesion molecules and toll-like receptors, exercise preconditioning is able to significantly reduce the amount of damage seen following ischemia/reperfusion injury. The underlying mechanism through which this process works focuses on the decreased leukocyte migration and diapedesis often seen in the reperfusion stage following stroke. Decreased leukocyte infiltration decreases many of the secondary changes such as free radical formation and subsequent edema formation. Ultimately, the decreased leukocyte invasion seen in exercise preconditioned subjects leads to better neurologic outcome following ischemia/reperfusion injury.

\subsection{Neuronal death and survival signalling pathways}

Neuronal survival depends on both external and internal stimuli and environments. Many of the changes following exercise preconditioning, involving inflammation, strengthening of the blood brain barrier, and increased integrity of the neurovascular unit, improve the cerebral environment in the setting of acute ischemia/reperfusion injury. In addition, internal cellular stimuli and pathways have a profound effect on neuronal survival. Following exercise preconditioning, apoptosis is attenuated and heat shock proteins are upregulated through a variety of biomolecular mechanisms following ischemia/reperfusion injury. Likewise, external stimuli through tumor necrosis factor (TNF)- $\alpha$ protect the brain during hypoxia. These changes seen in rats preconditioned with physical exercise are neuroprotective in the setting of ischemia/reperfusion injury, decreasing neuronal death and improving neurologic outcomes.

\subsubsection{Anti:Pro apoptotic ratio}

Neuronal apoptosis following ischemia/reperfusion injury is regulated by cascades of proand anti-apoptotic proteins. Notable among these include pro-apoptotic Bax, Bad, and Bak and anti-apoptotic Bcl-2 and Bcl-xL (Lazou et al., 2006; Mayer and Oberbauer, 2003). Upregulation of anti-apoptotic proteins (Bcl-2, Bcl-xL) and corresponding downregulation of pro-apoptotic proteins (Bax, Bad, and Bak) are seen following exercise preconditioning and are protective in the event of cerebral ischemia (Rybnikova et al., 2006; Wu et al., 2003). In addition to these key regulatory proteins, both caspase-dependent and caspase independent pathways appear to be involved in cerebral ischemia and neuronal death (Cao et al., 2003; Joza et al., 2001; Zhu et al., 2003), and apoptosis induced factor (AIF) also plays a key role in pro-apoptosis (Daugas et al., 2000; Susin et al., 1999).

Exercise preconditioning has been shown to not only enhance the expression of anti-apoptotic $\mathrm{Bcl}-\mathrm{xL}$, but to also decrease the expression of pro-apoptotic AIF and Bax, ultimately leading to decreased apoptosis and prolonged neuronal survival (Chaudhry et al., 2010). Following 
ischemia/reperfusion injury, this increased anti:pro apoptotic ratio generates decreased neuronal death and smaller infarct size. While these neuroprotective mechanisms of exercise are newly evolving, they provide a possible point of therapeutic intervention. While neuroprotective agents that target cell death pathways have been tried in the past, the potential for increasing cell survival reveals a potential novel strategy for improving outcomes following ischemia/reperfusion (Chan, 2004). This could provide a neuroprotective therapy that would simultaneously promote cell survival and decrease neuronal death, thus ameliorating much of the functional loss following acute ischemic stroke.

\subsubsection{TNF- $\alpha$ and TNF- $\alpha$ receptor}

Tumor necrosis factor (TNF)- $\alpha$ is a major deleterious pro-inflammatory cytokine found throughout the systemic circulation and upregulated following stroke and traumatic brain injury (Botchkina et al., 1997; Sairanen et al., 2001). Despite its inflammatory and injurious effects, evidence also points to TNF-a as a beneficial factor in tissue repair and neuroprotection (Bruce et al., 1996; Feuerstein and Wang, 2001; Wang et al., 2000). Furthermore, this cytokine may serve to induce endogenous neuroprotection following chronic exercise preconditioning. It is believed that exercise training produces a chronic low grade increase in TNF- $\alpha$ concentration, ultimately generating neuronal tolerance and protection in the setting of ischemia/reperfusion injury (Ginis et al., 1999; Liu et al., 2000; Wang et al., 2000). In a similar manner, TNF-a concentration was chronically elevated following exercise, which resulted in reduced myocardial infarction (Yamashita et al., 1999); however, acutely elevated levels of TNF- $\alpha$ following ischemia results in harmful myocardial remodelling (Jobe et al., 2009).

In the brain, exercise preconditioning also chronically increases the level of TNF-a that is exposed to neuronal cells, an effect which prevents the downstream inflammatory reaction which is induced by acutely elevated levels of TNF- $\alpha$ following cerebral ischemia/reperfusion injury (Ding et al., 2005). Furthermore, TNF-a has also been shown to reduce blood brain barrier injury and neuronal damage following ischemic stroke (Guo et al., 2008b). This scenario reveals two sides to the effect of TNF-a on neuronal survival and cerebral integrity. With chronic low levels of the cytokine, it is profoundly beneficial and neuroprotective; however, following ischemia/reperfusion, the acute increase of TNF-a into the cerebrovascular circulation destroys the integrity of the neurovascular unit, increases cell death, and enlarges the infarct volume. Exercise preconditioning enhances the former effect, increasing chronic low grade levels of the cytokine, which ameliorates the latter effect and dampens the injury following acute increases of TNF-a.

Mechanisms underlying this complex picture of TNF-a have not been completely uncovered, but are thought to involve the expression of TNF-a receptors. Previous studies have shown that the chronic exercise-induced levels of TNF-a serve to reduce the expression of TNF-a receptor after ischemia/reperfusion (Reyes, Jr. et al., 2006). Following ischemic injury in a rat model, pre-ischemic exercise was indeed found to decrease the expression of TNF-a receptors I and II, leading to reduced brain damage and enhance neurologic recovery (Reyes, Jr. et al., 2006). These results indicate a classic desensitization of the TNF-a receptor following exercise preconditioning, promoting neuronal tolerance to acutely elevated levels of TNF-a following ischemia/reperfusion injury.

\subsubsection{Heat shock proteins}

Neuronal survival and neuroprotection appears to be further driven by heat shock protein (HSP)-70, a highly inducible protein of $70 \mathrm{kDa}$. HSP-70 is well known to respond to various 
types of stress, including heat shock, hypoxia, oxidative stress, and exposure to metals and toxins (Kiang and Tsokos, 1998). Constitutively expressed, this molecular chaperone protein assists in the folding both nascent and denatured proteins during times of neuronal stress (Schlesinger, 1990). Overexpression of HSP-70 has previously been shown to be neuroprotective in the setting of ischemia/reperfusion (Giffard and Yenari, 2004). This neuroprotective protein interferes with apoptosis inducing factor (AIF), a pro-apoptotic protein. HSP-70 also increases the levels of anti-apoptotic proteins, Bcl-2 and Bcl-xL, thus serving as another mechanism to increase the anti:pro apoptotic ratio and push neurons toward cellular survival, especially in the setting of ischemia/reperfusion (Liebelt et al., 2010; Ohtsuka and Suzuki, 2000).

Multiple studies have shown that ischemic preconditioning induces HSP-70 expression and promotes neuroprotection (Chen and Simon, 1997; Kirino et al., 1991; Masada et al., 2001). Despite these benefits, the effects of HSP-70 are limited. If the insult is very severe or if expression of HSP-70 is too low, the beneficial effects may not be seen (Giffard and Yenari, 2004; Lee et al., 2001; Matsumori et al., 2005). Nonetheless, HSP-70 mice convey more potent neuroprotection than wild type mice, underlying its importance as a key factor in exercise-induced neuroprotection for ischemia/reperfusion injury (Matsumori et al., 2005). In addition to its neuroprotective effects, HSP-70 has also been seen to be cardioprotective following upregulation after exercise preconditioning (Hamilton et al., 2003; Lennon et al., 2004).

Also, HSP-70 alone does not appear to be neuroprotective, but it requires other proteins for optimal neuroprotection (Lee et al., 2001). Upregulation of TNF- $\alpha$ appears to be critical for HSP-70 to effectively reduce apoptosis and prolong neuronal survival (Liebelt et al., 2010). Furthermore, TNF-a and HSP-70 appear to work in concert through an ERK1/2 signal transduction pathway to increase the expression of anti-apoptotic genes and decrease the expression of pro-apoptotic genes (Goel et al., 2010). These results reveal the neuroprotective nature of HSP-70, but they also reveal its limitations. For HSP-70 to truly be effective in the setting of ischemia/reperfusion injury, it requires a large insult, significant HSP-70 expression, and the upregulation of other proteins as well, including TNF-a. Despite these constraints, HSP-70 does appear to induce neuroprotection in ischemia/reperfusion injury following exercise preconditioning.

\subsection{Extracellular signal-regulated kinase}

Extracellular signal-regulated kinases (ERK1/2) are involved in mitogen-activated protein kinase pathways and are constitutively expressed in the adult brain (Fiore et al., 1993; Sharony et al., 2005). These ERK1/2-regulated pathways are pivotal in signal transduction and neuroprotection in the setting of ischemia/reperfusion injury. Numerous studies have shown a pro-apoptotic role for ERK1/2 in neurons and other cells as well (Chu et al., 2004; Shackelford and Yeh, 2006; Zhuang and Schnellmann, 2006). Although ERK1/2 has been shown to push cells towards death, a protective and beneficial role has also been established (Rybnikova et al., 2006). Activation of this regulatory kinase has been shown to enable tissue repair in the setting of ischemia/reperfusion injury, thus decreasing cell death (Cavanaugh, 2004; Hetman and Gozdz, 2004; Ostrakhovitch and Cherian, 2005; Sawatzky et al., 2006). Furthermore, exercise preconditioning appears to upregulate ERK1/2, leading to an ischemic neuronal tolerance under hypoxic condition (Gu et al., 2001; Jones and Bergeron, 2004; Shamloo and Wieloch, 1999). While ERK1/2 is upregulated following ischemic 
preconditioning (Lecour et al., 2005), ERK1/2 activation also is detrimental following stroke, trauma and degenerative disease (Chu et al., 2004). This dual role of ERK1/2, being both beneficial and detrimental, may be similar in mechanism to the effects of TNF- $\alpha$ in which chronic upregulation following exercise preconditioning generates neuronal tolerance and improved outcome following ischemia/reperfusion injury.

Following inhibition of ERK1/2 in exercise preconditioned animals, neuroprotection was substantially reduced in ischemia/reperfusion, suggesting the pertinent role of ERK1/2 in exercise-induced neuroprotection (Guo et al., 2008b). However, exercise preconditioned animals did have elevated levels of ERK1/2 and TNF- $\alpha$ following exercise training, which correlated with decreased neurologic deficit, smaller brain infarcts, and less inflammation (Curry et al., 2009). A recent study has shown that ERK1/2 activation also helps to regulate apoptosis (Liebelt et al., 2010). Again, pre-ischemic exercise led to minor increases in ERK1/2, which was neuroprotective against the large acute elevations seen following ischemia/reperfusion injury. In the setting of hypoxic injury, ERK1/2 regulates the anti- and pro-apoptotic pathways involving such regulators as Bcl-xL, Bax, and AIF. Following exercise preconditioning, the upregulation of ERK1/2 served to promote anti-apoptosis, leading to decreased neuronal apoptosis and infarct volume.

ERK1/2, while shown to ameliorate ischemia/reperfusion through its apoptotic regulatory effects and inflammatory changes, has also been linked with HSP-70 and TNF$\alpha$. Several studies have shown these three important proteins to be fundamentally linked in a relationship where TNF- $\alpha$ and HSP-70 activate the MEK/ERK signalling pathway, leading to neuroprotection (Gortz et al., 2005; Lee et al., 2001,2005). While ischemic preconditioning has been shown to induce ERK1/2-mediated neuroprotection, pharmacologic pre-treatment with TNF- $\alpha$ has not shown similar results (Lecour et al., 2005), suggesting that multiple interacting pathways and proteins are likely necessary to observe the full neuroprotective effect. It seems likely that a cross talk between TNF- $\alpha$, HSP-70, and ERK1/2 occurs in exercise training, allowing for a greater neuroprotective response following ischemia/reperfusion injury. Nonetheless, these studies have clarified a dual role of ERK1/2 in neuroprotection, in which chronic low levels protect against acute elevations of the protein and ameliorate the damage and neuronal loss following ischemia/reperfusion injury.

\subsection{Metabolic enhancement}

The association between exercise preconditioning and neuroprotection in ischemia/reperfusion has been well established. In addition to the aforementioned mechanisms, chronic exercise training also affects cerebral metabolism and energy production, allowing neurons to re-establish homeostasis more rapidly following acute ischemic stroke. A recent study revealed that forced exercise resulted in enhanced cerebral glycolysis and cerebral metabolism (Kinni et al., 2011). In addition to increasing glycolysis, exercise preconditioning is also well known to increase cerebral blood flow (CBF) and adenosine triphosphate (ATP) production (Ide and Secher, 2000; McCloskey et al., 2001; Ogoh and Ainslie, 2009). Exercise can be best viewed as a chronic state of metabolic stress, which requires increased glucose delivery, glycolysis, and ATP production in order to match the energy demand. Chronic exercise preconditioning enables the neuronal cells to accumulate the necessary machinery for mass ATP production, which elevates the metabolic and ATP production potential in these cells. In the setting of ischemia/reperfusion injury, 
these preconditioned neurons have an increased metabolic capacity and are better able to avoid hypoxic damage.

\subsubsection{ATP production}

The process of ATP production requires several key steps, involving detection of low ATP stores, glucose transport and glycolysis. 5'-AMP-activated protein kinase (AMPK) serves as an energy sensor and is capable of detecting low ATP stores in cells (Minchenko et al., 2003). The protein is a heterotrimeric serine/threonine kinase, which becomes activated in times of metabolic stress and decreased ATP stores (Emerling et al., 2007; Hardie et al., 2003; Zorzano et al., 2005). When ATP concentrations drop, AMPK activates glycolysis in order to restore the cell's energy balance, allowing it to serve as an excellent marker of metabolic demand (Kahn et al., 2005). Following exercise training, levels of the active phosphorylated form of AMPK are increased in response to the elevated metabolic demand (Aschenbach et al., 2004; Kinni et al., 2011). Following ischemia/reperfusion injury, the active phosphorylated form of AMPK has been shown to be upregulated in preconditioned rats, suggesting an increased metabolic response to hypoxia in these exercised animals (unpublished data). This increased capacity for metabolism upregulation is mirrored in elevated levels of glucose transporters and glycolytic enzymes, which are also seen following exercise training and correlate with better outcomes following ischemia/reperfusion injury.

While increases in cerebral blood flow associated with exercise facilitate greater transport of glucose to the neurovascular system, transport across the BBB and neuronal membrane are controlled by glucose transporters (GLUT). GLUT1 is primarily found in the endothelial cells of the BBB and generates a basal glucose level, while GLUT3 is found exclusively in neurons, and both of these glucose transporters have previously been shown to increase in response to hypoxia and elevated metabolic demand (Maurer et al., 2006). The increased need for energy production following hypoxia requires more glucose to be available within neurons, and these two glucose transporters work together to shuttle glucose from the circulation into neurons. GLUT1 and GLUT3 are known to have increased expression following exercise preconditioning (Kinni et al., 2011). Following ischemia/reperfusion injury, GLUT1 and GLUT3 levels are elevated in the first 4 hours after reperfusion is established in exercise preconditioned rats, but expression is equal to control at 24 hours after injury (unpublished data). This elevation in GLUT expression in the acute phase of reperfusion indicates that these preconditioned animals have the cellular machinery in place immediately when it is needed. Non-exercised rats take longer to transcribe and translate the needed metabolic proteins, leading to increased metabolic dysfunction. Thus, exercise preconditioning provides neuroprotection by increasing the levels of available glucose within neurons, providing the necessary substrate for ATP production.

Once inside neurons, glucose must be metabolized to produce ATP for the cell. The initial steps of glycolysis are primarily regulated by the key rate limiting step of phosphofructokinase (PFK), which catalyzes the phosphorylation of fructose-6-phosphate to fructose-1,6-bisphosphonate. PFK expression is known to be upregulated following increased metabolism and glycolysis and is has been shown to be neuroprotective in hypoglycemic conditions (Minchenko et al., 2003). Another study has revealed PFK is increased following exercise preconditioning (Kinni et al., 2011), and this enzyme is 
increased following ischemia/reperfusion injury, leading to increased neuronal metabolism and decreased neurologic deficits (unpublished data). The elevated ability of neurons to process glucose through glycolysis in exercise preconditioned animals underlies another key component of exercise-induced neuroprotection. Not only does exercise training increase glucose delivery to cells through angiogenesis and glucose transport, it also upregulates the machinery needed for glucose breakdown and ATP production.

Ultimately, these processes work to increase ATP production to meet the energy demand of neurons. One test used to assess the ATP production capacity of a neuron is an ADP:ATP ratio, which has been found to be decreased following ischemia/reperfusion injury in exercise preconditioned rats (unpublished data). A lower ADP:ATP ratio indicates a lower level of metabolic dysfunction and increased capacity for ATP production in exercise trained rats. Through the increased expression of various metabolic proteins, including AMPK, GLUT1, GLUT3, and PFK, exercise preconditioning upregulates multiple stages of ATP production, providing cells with the important energy substrate. The increased capacity for ATP production allows neurons in exercise trained rats to decrease their energy deficit following ischemia/reperfusion injury. In turn, this promotes neuronal survival and decreases infarct size, leading to better outcomes following ischemia/reperfusion.

\subsubsection{HIF- $1 \alpha$ and metabolism}

Hypoxic-induced factor- $1 \alpha$ (HIF-1 $\alpha$ ) is a transcription factor, which is normally inhibited by oxygen-dependent hydroxylase enzymes, but in hypoxic conditions, these hydroxylase enzymes lose their ability to function and allow HIF-1 $\alpha$ to initiate gene transcription (Bracken et al., 2006). HIF-1 $\alpha$ is known to be neuroprotective in rats following ischemia/reperfusion injury (Bernaudin et al., 2002; Schubert, 2005). Not only is HIF-1 $\alpha$ increased following hypoxia, but it also is increased in rats that are chronically exposed to hypoxic events (Bernaudin et al., 2002; Bracken et al., 2006). The expression of HIF-1 $\alpha$ is also known to be increased following exercise preconditioning (Kinni et al., 2011). In addition to these findings, the transcription factor has also been shown to increase the expression of genes and proteins involved in angiogenesis and glycolysis, revealing its metabolism promoting activity (Bergeron et al., 1999; Bernaudin et al., 2002; Iyer et al., 1998; Jones and Bergeron, 2001; Schubert, 2005; Semenza, 2009). HIF-1 $\alpha$ is known to increase the expression of VEGF, glucose transporters and enzymes involved in glycolysis, such as PFK (Bergeron et al., 1999; Jones and Bergeron, 2001; Kim et al., 2006). HIF-1 $\alpha$ is not only involved in enhanced expression of metabolic enzymes and pathways, but the expression of HIF-1 $\alpha$ is also increased by AMPK, a master regulator of neuronal metabolism (Emerling et al., 2007; Lee et al., 2003; Neurath et al., 2006). In fact, studies in chronically exercised rats have demonstrated that increased levels of AMPK induce HIF-1 $\alpha$ to increase the expression of glucose transporters and PFK (Emerling et al., 2007; Hardie et al., 2003; Kahn et al., 2005; McGee and Hargreaves, 2006).

HIF-1 $\alpha$, through its multiple mechanistic pathways, can increase metabolism and angiogenesis in an oxygen-deficient state, allowing it to simultaneously increase the mode of glucose delivery and the mechanism of ATP production. In addition to being increased following exercise preconditioning (Kinni et al., 2011), HIF-1 $\alpha$ is also increased in exercise trained animals following ischemia/reperfusion injury, which correlated with better neurologic outcomes and decreased infarct size (unpublished data). These results indicate 
that exercise equips neurons with a greater ability to upregulated glucose transport and metabolism, resulting in greater ATP production and decreased metabolic dysfunction, following acute ischemic stroke. This rapid response to an elevated energy demand promotes neuronal recovery and survival and serves as another mechanism of exerciseinduced neuroprotection in the setting of ischemia/reperfusion injury.

\section{Clinical implications}

Exercise-induced preconditioning is useful in prevention and amelioration of neuronal loss and neurologic dysfunction following ischemia/reperfusion injury, but it also has many therapeutic implications as well. The potential for future drug targets at various levels of the neuroprotective mechanisms are abundant as the effects of neurotrophic factors, neurovascular unit integrity, inflammatory markers, and metabolic changes provide potential avenues for future pharmacologic intervention. Particularly evident in patients with a history of ischemic stroke, traumatic brain injury, or transient ischemic attacks, pharmacologic interventions that could increase metabolism, strengthen the neurovascular unit, or decrease inflammation could have profound effects on morbidity and mortality associated with cerebrovascular accidents. Finally, the implications for exercise preconditioning prior to neurosurgical intervention can clearly be seen. Through its ability to strengthen the neurovascular unit and decrease brain inflammation, exercise training should be strongly encouraged in any individuals prior to neurosurgical intervention.

\section{Conclusion}

Exercise preconditioning clearly is neuroprotective in the setting of ischemia/reperfusion injury, and these protective effects are conveyed through multiple mechanisms. The neuroprotection derived as a result of exercise training is an endogenous effect that occurs independently of the risk factor modification that is also seen following exercise. Innate neuroprotection from exercise is derived from elevated levels of neurotrophin proteins, which increase neuronal abundance and strength. Furthermore, enhanced integrity of the neurovascular unit occurs through strengthening of the blood brain barrier, astrocytosis, angiogenesis, and arteriogenesis. Exercise preconditioning also decreases the inflammatory response and leukocyte invasion following ischemia/reperfusion injury, thus decreasing much of the secondary damage seen following the reperfusion stage. Neuronal apoptosis is reduced as exercise training increases anti-apoptotic factors and simultaneously decreases pro-apoptotic factors, pushing neurons towards a state of survival rather than programmed cell death. Finally, exercise increases the metabolic capacity of neurons through upregulation of cerebral blood flow, glucose transport, glycolysis, and ATP production. Altogether, these changes seen following exercise preconditioning decreased neuronal loss, reduce infarct volume, and improve neurologic outcomes after ischemia/reperfusion injury.

\section{References}

Ang, E. T., P. T. Wong, S. Moochhala, and Y. K. Ng, 2003, Neuroprotection associated with running: is it a result of increased endogenous neurotrophic factors?: Neuroscience, v. 118 , no. 2, p. 335-345. 
Arai, K., S. R. Lee, and E. H. Lo, 2003, Essential role for ERK mitogen-activated protein kinase in matrix metalloproteinase- 9 regulation in rat cortical astrocytes: Glia, v. 43, no. 3, p. 254-264.

Asahi, M., X. Wang, T. Mori, T. Sumii, J. C. Jung, M. A. Moskowitz, M. E. Fini, and E. H. Lo, 2001, Effects of matrix metalloproteinase-9 gene knock-out on the proteolysis of blood-brain barrier and white matter components after cerebral ischemia: J Neurosci, v. 21, no. 19, p. 7724-7732.

Aschenbach, W. G., K. Sakamoto, and L. J. Goodyear, 2004, 5' adenosine monophosphateactivated protein kinase, metabolism and exercise: Sports Med., v. 34, no. 2, p. 91103.

Aspey, B. S., C. Jessimer, S. Pereira, and M. J. Harrison, 1989, Do leukocytes have a role in the cerebral no-reflow phenomenon?: J Neurol Neurosurg Psychiatry, v. 52, no. 4, p. 526-528.

Ayata, C., and A. H. Ropper, 2002, Ischaemic brain oedema: J Clin Neurosci, v. 9, no. 2, p. 113-124.

Bergeron, M., A. Y. Yu, K. E. Solway, G. L. Semenza, and F. R. Sharp, 1999, Induction of hypoxia-inducible factor-1 (HIF-1) and its target genes following focal ischaemia in rat brain: Eur.J.Neurosci., v. 11, no. 12, p. 4159-4170.

Bernaudin, M., A. S. Nedelec, D. Divoux, E. T. MacKenzie, E. Petit, and P. Schumann-Bard, 2002, Normobaric hypoxia induces tolerance to focal permanent cerebral ischemia in association with an increased expression of hypoxia-inducible factor- 1 and its target genes, erythropoietin and VEGF, in the adult mouse brain: J.Cereb.Blood Flow Metab, v. 22, no. 4, p. 393-403.

Black, J. E., K. R. Isaacs, B. J. Anderson, A. A. Alcantara, and W. T. Greenough, 1990, Learning causes synaptogenesis, whereas motor activity causes angiogenesis, in cerebellar cortex of adult rats: Proceedings of the National Academy of Sciences of the United States of America, v. 87, no. 14, p. 5568-5572.

Botchkina, G. I., M. E. Meistrell, I. L. Botchkina, and K. J. Tracey, 1997, Expression of TNF and TNF receptors (p55 and p75) in the rat brain after focal cerebral ischemia: Mol Med, v. 3, no. 11, p. 765-781.

Bracken, C. P., A. O. Fedele, S. Linke, W. Balrak, K. Lisy, M. L. Whitelaw, and D. J. Peet, 2006, Cell-specific regulation of hypoxia-inducible factor (HIF)-1alpha and HIF2alpha stabilization and transactivation in a graded oxygen environment: J.Biol.Chem., v. 281, no. 32, p. 22575-22585.

Bruce, A. J., W. Boling, M. S. Kindy, J. Peschon, P. J. Kraemer, M. K. Carpenter, F. W. Holtsberg, and M. P. Mattson, 1996, Altered neuronal and microglial responses to excitotoxic and ischemic brain injury in mice lacking TNF receptors: Nat Med, v. 2, no. 7, p. 788-794.

Cao, C. X., Q. W. Yang, F. L. Lv, J. Cui, H. B. Fu, and J. Z. Wang, 2007, Reduced cerebral ischemia-reperfusion injury in Toll-like receptor 4 deficient mice: Biochem.Biophys.Res.Commun., v. 353, no. 2, p. 509-514.

Cao, G., R. S. Clark, W. Pei, W. Yin, F. Zhang, F. Y. Sun, S. H. Graham, and J. Chen, 2003, Translocation of apoptosis-inducing factor in vulnerable neurons after transient cerebral ischemia and in neuronal cultures after oxygen-glucose deprivation: J Cereb.Blood Flow Metab, v. 23, no. 10, p. 1137-1150. 
Cavanaugh, J. E., 2004, Role of extracellular signal regulated kinase 5 in neuronal survival: Eur.J.Biochem., v. 271, no. 11, p. 2056-2059.

Chan, P. H., 2004, Future targets and cascades for neuroprotective strategies: Stroke, v. 35, no. 11 Suppl 1, p. 2748-2750.

Chaudhry, K. et al., 2010, Matrix metalloproteinase-9 (MMP-9) expression and extracellular signal-regulated kinase 1 and 2 (ERK1/2) activation in exercise-reduced neuronal apoptosis after stroke: Neuroscience Letters, v. 474, no. 2, p. 109-114.

Chen, J., and R. Simon, 1997, Ischemic tolerance in the brain: Neurology, v. 48, no. 2, p. 306311.

Choudhri, T. F., B. L. Hoh, H. G. Zerwes, C. J. Prestigiacomo, S. C. Kim, E. S. Connolly, Jr, G. Kottirsch, and D. J. Pinsky, 1998, Reduced microvascular thrombosis and improved outcome in acute murine stroke by inhibiting GP IIb/IIIa receptormediated platelet aggregation: Journal of Clinical Investigation, v. 102, no. 7, p. 1301-1310.

Chu, C. T., D. J. Levinthal, S. M. Kulich, E. M. Chalovich, and D. B. DeFranco, 2004, Oxidative neuronal injury. The dark side of ERK1/21: Eur.J Biochem., v. 271, no. 11, p. 2060-2066.

Clark, A. W., C. A. Krekoski, S. S. Bou, K. R. Chapman, and D. R. Edwards, 1997, Increased gelatinase A (MMP-2) and gelatinase B (MMP-9) activities in human brain after focal ischemia: Neurosci Lett, v. 238, no. 1-2, p. 53-56.

Cohen-Cory, S., A. H. Kidane, N. J. Shirkey, and S. Marshak, 2010, Brain-derived neurotrophic factor and the development of structural neuronal connectivity: Dev.Neurobiol., v. 70, no. 5, p. 271-288.

Curry, A. et al., 2009, Exercise pre-conditioning reduces brain inflammation in stroke via tumor necrosis factor-alpha, extracellular signal-regulated kinase $1 / 2$ and matrix metalloproteinase-9 activity: Neurological Research.

Dans, M. J., and F. G. Giancotti, 1999,Dans, M. J., and F. G. Giancotti Guidebook to the extracellular matrix, anchor, and adhesion proteins: Oxford, Sambrook \& Tooze Publication at Osford University Press.

Daugas, E. et al., 2000, Mitochondrio-nuclear translocation of AIF in apoptosis and necrosis: FASEB J, v. 14, no. 5, p. 729-739.

Davis, W., S. Mahale, A. Carranza, B. Cox, K. Hayes, D. Jimenez, and Y. Ding, 2007, Exercise pre-conditioning ameliorates blood-brain barrier dysfunction in stroke by enhancing basal lamina: Neurological Research, v. 29, no. 4, p. 382-387.

del Zoppo, G. J., and J. M. Hallenbeck, 2000, Advances in the vascular pathophysiology of ischemic stroke: Thromb Res, v. 98, no. 3, p. 73-81.

del Zoppo, G. J., and T. Mabuchi, 2003, Cerebral microvessel responses to focal ischemia: J Cereb Blood Flow Metab, v. 23, no. 8, p. 879-894.

Dietrich, W. D., R. Busto, S. Yoshida, and M. D. Ginsberg, 1987, Histopathological and hemodynamic consequences of complete versus incomplete ischemia in the rat: J Cereb Blood Flow Metab, v. 7, no. 3, p. 300-308.

Ding, Y, Y H Ding, J Li, J A Rafols. Exercise induces integrin overexpression and improves neurovascular integrity in ischemic stroke. Stroke 36[2], 470. 2005. Ref Type: Abstract 
Ding, Y., J. Li, J. Clark, F. G. Diaz, and J. A. Rafols, 2003, Synaptic plasticity in thalamic nuclei enhanced by motor skill training in rat with transient middle cerebral artery occlusion: Neurological Research, v. 25, p. 189-194.

Ding, Y., J. Li, X. Luan, Y. H. Ding, Q. Lai, J. A. Rafols, J. W. Phillis, J. Clark, and F. G. Diaz, 2004a, Exercise Pre-conditioning Reduces Brain Damage in Ischemic Rats That May be Associated with Regional Angiogenesis and Cellular Overexpression of Neurotrophin: Neuroscience, v. 124, p. 583-591.

Ding, Y. H., Y. Ding, J. Li, D. A. Bessert, and J. A. Rafols, 2006a, Exercise pre-conditioning strengthens brain microvascular integrity in a rat stroke model: Neurol Res, v. 28, no. 2, p. 184-189.

Ding, Y. H., J. Li, W. X. Yao, J. A. Rafols, J. C. Clark, and Y. Ding, 2006b, Exercise preconditioning upregulates cerebral integrins and enhances cerebrovascular integrity in ischemic rats: Acta Neuropathol.(Berl), v. 112, no. 1, p. 74-84.

Ding, Y. H., X. Luan, J. Li, J. A. Rafols, M. Guthikonda, F. G. Diaz, and Y. Ding, 2004b, Exercise-induced overexpression of angiogenic factors and reduction of ischemia/reperfusion injury in stroke: Current Neurovascular Research, v. 1, no. 5, p. 411-420.

Emerling, B. M., B. Viollet, K. V. Tormos, and N. S. Chandel, 2007, Compound C inhibits hypoxic activation of HIF-1 independent of AMPK: FEBS Lett., v. 581, no. 29, p. 5727-5731.

Evenson, K. R., W. D. Rosamond, J. Cai, J. F. Toole, R. G. Hutchinson, E. Shahar, and A. R. Folsom, 1999, Physical activity and ischemic stroke risk. The atherosclerosis risk in communities study: Stroke, v. 30, no. 7, p. 1333-1339.

Feuerstein, G. Z., and X. Wang, 2001, Inflammation and stroke: benefits without harm?: Arch Neurol, v. 58, no. 4, p. 672-674.

Fiore, R. S., V. E. Bayer, S. L. Pelech, J. Posada, J. A. Cooper, and J. M. Baraban, 1993, p42 mitogen-activated protein kinase in brain: prominent localization in neuronal cell bodies and dendrites: Neuroscience, v. 55, no. 2, p. 463-472.

Gasche, Y., M. Fujimura, F. Morita, J. C. Copin, M. Kawase, J. Massengale, and P. H. Chan, 1999, Early appearance of activated matrix metalloproteinase-9 after focal cerebral ischemia in mice: a possible role in blood-brain barrier dysfunction: J Cereb Blood Flow Metab, v. 19, no. 9, p. 1020-1028.

Giffard, R. G., and M. A. Yenari, 2004, Many mechanisms for hsp70 protection from cerebral ischemia: J Neurosurg Anesthesiol., v. 16, no. 1, p. 53-61.

Gillum, R. F., M. E. Mussolino, and D. D. Ingram, 1996, Physical activity and stroke incidence in women and men. The NHANES I Epidemiologic Follow-up Study: Am J Epidemiol, v. 143, no. 9, p. 860-869.

Ginis, I., U. Schweizer, M. Brenner, J. Liu, N. Azzam, M. Spatz, and J. M. Hallenbeck, 1999, TNF-alpha pretreatment prevents subsequent activation of cultured brain cells with TNF-alpha and hypoxia via ceramide: Am J Physiol, v. 276, no. 5 Pt 1, p. C1171C1183.

Gleeson, M., B. McFarlin, and M. Flynn, 2006, Exercise and Toll-like receptors: Exerc.Immunol.Rev., v. 12, p. 34-53.

Goel, G., M. Guo, J. Ding, D. Dornbos, III, A. Ali, M. Shenaq, M. Guthikonda, and Y. Ding, 2010, Combined effect of tumor necrosis factor (TNF)-alpha and heat shock protein 
(HSP)-70 in reducing apoptotic injury in hypoxia: a cell culture study: Neuroscience Letters, v. 483, no. 3, p. 162-166.

Gortz, B., S. Hayer, B. Tuerck, J. Zwerina, J. S. Smolen, and G. Schett, 2005, Tumour necrosis factor activates the mitogen-activated protein kinases p38alpha and ERK in the synovial membrane in vivo: Arthritis Res Ther., v. 7, no. 5, p. R1140R1147.

Gu, Z., Q. Jiang, and G. Zhang, 2001, Extracellular signal-regulated kinase 1/2 activation in hippocampus after cerebral ischemia may not interfere with postischemic cell death: Brain Research, v. 901, no. 1-2, p. 79-84.

Guo, M., B. Cox, S. Mahale, W. Davis, A. Carranza, K. Hayes, S. Sprague, D. Jimenez, and Y. Ding, 2008a, Pre-ischemic exercise reduces matrix metalloproteinase-9 expression and ameliorates blood-brain barrier dysfunction in stroke: Neuroscience, v. 151, no. 2, p. 340-351.

Guo, M., V. Lin, W. Davis, T. Huang, A. Carranza, S. Sprague, R. Reyes, D. Jimenez, and Y. Ding, 2008b, Preischemic induction of TNF-alpha by physical exercise reduces blood-brain barrier dysfunction in stroke: J.Cereb.Blood Flow Metab, v. 28, no. 8, p. $1422-1430$.

Hamilton, K. L., J. L. Staib, T. Phillips, A. Hess, S. L. Lennon, and S. K. Powers, 2003, Exercise, antioxidants, and HSP72: protection against myocardial ischemia/reperfusion: Free Radic.Biol Med, v. 34, no. 7, p. 800-809.

Hardie, D. G., J. W. Scott, D. A. Pan, and E. R. Hudson, 2003, Management of cellular energy by the AMP-activated protein kinase system: FEBS Lett., v. 546, no. 1, p. 113120.

Hayes, K., S. Sprague, M. Guo, W. Davis, A. Friedman, A. Kumar, D. F. Jimenez, and Y. Ding, 2008, Forced, not voluntary, exercise effectively induces neuroprotection in stroke: Acta Neuropathologica, v. 115, no. 3, p. 289-296.

Hellstrom, G., C. Fischer, N. G. Wahlgren, and T. Jogestrand, 1996, Carotid artery blood flow and middle cerebral artery blood flow velocity during physical exercise: J Appl Physiol, v. 81, no. 1, p. 413-418.

Hetman, M., and A. Gozdz, 2004, Role of extracellular signal regulated kinases 1 and 2 in neuronal survival: Eur.J.Biochem., v. 271, no. 11, p. 2050-2055.

Hosomi, N., C. R. Ban, T. Naya, T. Takahashi, P. Guo, X. Y. Song, and M. Kohno, 2005, Tumor necrosis factor-alpha neutralization reduced cerebral edema through inhibition of matrix metalloproteinase production after transient focal cerebral ischemia

2: J Cereb.Blood Flow Metab, v. 25, no. 8, p. 959-967.

Hu, G., N. C. Barengo, J. Tuomilehto, T. A. Lakka, A. Nissinen, and P. Jousilahti, 2004, Relationship of physical activity and body mass index to the risk of hypertension: a prospective study in Finland: Hypertension, v. 43, no. 1, p. 25-30.

Hu, G., C. Sarti, P. Jousilahti, K. Silventoinen, N. C. Barengo, and J. Tuomilehto, 2005, Leisure time, occupational, and commuting physical activity and the risk of stroke: Stroke, v. 36, no. 9, p. 1994-1999.

Hynes, R. O., 1992, Integrins: versatility, modulation, and signaling in cell adhesion: Cell, v. 69 , no. 1, p. 11-25. 
Ickes, B. R., T. M. Pham, L. A. Sanders, D. S. Albeck, A. H. Mohammed, and A. C. Granholm, 2000, Long-term environmental enrichment leads to regional increases in neurotrophin levels in rat brain: Exp Neurol, v. 164, no. 1, p. 45-52.

Ide, K., and N. H. Secher, 2000, Cerebral blood flow and metabolism during exercise: Prog Neurobiol, v. 61, no. 4, p. 397-414.

Igarashi, Y. et al., 1999, Glial cell line-derived neurotrophic factor induces barrier function of endothelial cells forming the blood-brain barrier: Biochem Biophys Res Commun, v. 261, no. 1, p. 108-112.

Isaacs, K. R., B. J. Anderson, A. A. Alcantara, J. E. Black, and W. T. Greenough, 1992, Exercise and the brain: angiogenesis in the adult rat cerebellum after vigorous physical activity and motor skill learning: J Cereb Blood Flow Metab, v. 12, no. 1, p. 110-119.

Iyer, N. V. et al., 1998, Cellular and developmental control of O2 homeostasis by hypoxiainducible factor 1 alpha: Genes Dev., v. 12, no. 2, p. 149-162.

Janzer, R. C., and M. C. Raff, 1987, Astrocytes induce blood-brain barrier properties in endothelial cells: Nature, v. 325, no. 6101, p. 253-257.

Jobe, L. J., G. C. Melendez, S. P. Levick, Y. Du, G. L. Brower, and J. S. Janicki, 2009, TNF-alpha inhibition attenuates adverse myocardial remodeling in a rat model of volume overload: Am.J.Physiol Heart Circ.Physiol, v. 297, no. 4, p. H1462H1468.

Jones, N. M., and M. Bergeron, 2004, Hypoxia-induced ischemic tolerance in neonatal rat brain involves enhanced ERK1/2 signaling: Journal of Neurochemistry, v. 89, no. 1, p. 157-167.

Jones, N. M., and M. Bergeron, 2001, Hypoxic preconditioning induces changes in HIF-1 target genes in neonatal rat brain: J.Cereb.Blood Flow Metab, v. 21, no. 9, p. 11051114.

Jones, T. A., C. J. Chu, L. A. Grande, and A. D. Gregory, 1999, Motor skills training enhances lesion-induced structural plasticity in the motor cortex of adult rats: J Neurosci, v. 19, no. 22, p. 10153-10163.

Joza, N. et al., 2001, Essential role of the mitochondrial apoptosis-inducing factor in programmed cell death: Nature, v. 410, no. 6828, p. 549-554.

Kahn, B. B., T. Alquier, D. Carling, and D. G. Hardie, 2005, AMP-activated protein kinase: ancient energy gauge provides clues to modern understanding of metabolism: Cell Metab, v. 1, no. 1, p. 15-25.

Kiang, J. G., and G. C. Tsokos, 1998, Heat shock protein 70 kDa: molecular biology, biochemistry, and physiology: Pharmacol.Ther., v. 80, no. 2, p. 183-201.

Kim, H., Q. Li, B. L. Hempstead, and J. A. Madri, 2004, Paracrine and autocrine functions of brain-derived neurotrophic factor (BDNF) and nerve growth factor (NGF) in brainderived endothelial cells: J.Biol.Chem., v. 279, no. 32, p. 33538-33546.

Kim, H. L., E. J. Yeo, Y. S. Chun, and J. W. Park, 2006, A domain responsible for HIF-1alpha degradation by YC-1, a novel anticancer agent: Int.J.Oncol., v. 29, no. 1, p. 255260.

Kinni, H., M. Guo, J. Y. Ding, S. Konakondla, D. Dornbos, III, R. Tran, M. Guthikonda, and Y. Ding, 2011, Cerebral metabolism after forced or voluntary physical exercise: Brain Research, v. 1388, p. 48-55. 
Kirino, T., Y. Tsujita, and A. Tamura, 1991, Induced tolerance to ischemia in gerbil hippocampal neurons: J Cereb.Blood Flow Metab, v. 11, no. 2, p. 299-307.

Kleim, J. A., N. R. Cooper, and P. M. VandenBerg, 2002, Exercise induces angiogenesis but does not alter movement representations within rat motor cortex: Brain Res, v. 934, no. 1, p. 1-6.

Kloner, R. A., 2001, Preinfarct angina and exercise: yet another reason to stay physically active: J.Am.Coll.Cardiol., v. 38, no. 5, p. 1366-1368.

Kondo, T., H. Kinouchi, M. Kawase, and T. Yoshimoto, 1996, Astroglial cells inhibit the increasing permeability of brain endothelial cell monolayer following hypoxia/reoxygenation: Neurosci Lett, v. 208, no. 2, p. 101-104.

Kuipers, S. D., and C. R. Bramham, 2006, Brain-derived neurotrophic factor mechanisms and function in adult synaptic plasticity: new insights and implications for therapy: Curr.Opin.Drug Discov.Devel., v. 9, no. 5, p. 580-586.

Larson, E. B., L. Wang, J. D. Bowen, W. C. McCormick, L. Teri, P. Crane, and W. Kukull, 2006, Exercise is associated with reduced risk for incident dementia among persons 65 years of age and older: Ann.Intern.Med., v. 144, no. 2, p. 73-81.

Lazou, A., E. K. Iliodromitis, D. Cieslak, K. Voskarides, S. Mousikos, E. Bofilis, and D. T. Kremastinos, 2006, Ischemic but not mechanical preconditioning attenuates ischemia/reperfusion induced myocardial apoptosis in anaesthetized rabbits: the role of Bcl-2 family proteins and ERK1/2: Apoptosis., v. 11, no. 12, p. 21952204.

Leasure, J. L., and M. Jones, 2008, Forced and voluntary exercise differentially affect brain and behavior: Neuroscience, v. 156, no. 3, p. 456-465.

Lecour, S., N. Suleman, G. A. Deuchar, S. Somers, L. Lacerda, B. Huisamen, and L. H. Opie, 2005, Pharmacological preconditioning with tumor necrosis factor-alpha activates signal transducer and activator of transcription-3 at reperfusion without involving classic prosurvival kinases (Akt and extracellular signal-regulated kinase): Circulation, v. 112, no. 25, p. 3911-3918.

Lee, J. E., M. A. Yenari, G. H. Sun, L. Xu, M. R. Emond, D. Cheng, G. K. Steinberg, and R. G. Giffard, 2001, Differential neuroprotection from human heat shock protein 70 overexpression in in vitro and in vivo models of ischemia and ischemia-like conditions: Exp.Neurol, v. 170, no. 1, p. 129-139.

Lee, J. S., J. J. Lee, and J. S. Seo, 2005, HSP70 deficiency results in activation of c-Jun Nterminal Kinase, extracellular signal-regulated kinase, and caspase-3 in hyperosmolarity-induced apoptosis: J Biol Chem., v. 280, no. 8, p. 6634-6641.

Lee, M., J. T. Hwang, H. J. Lee, S. N. Jung, I. Kang, S. G. Chi, S. S. Kim, and J. Ha, 2003, AMP-activated protein kinase activity is critical for hypoxia-inducible factor-1 transcriptional activity and its target gene expression under hypoxic conditions in DU145 cells: J.Biol.Chem., v. 278, no. 41, p. 39653-39661.

Lennon, S. L., J. Quindry, K. L. Hamilton, J. French, J. Staib, J. L. Mehta, and S. K. Powers, 2004, Loss of exercise-induced cardioprotection after cessation of exercise: J Appl.Physiol, v. 96, no. 4, p. 1299-1305.

Li, J., Y. H. Ding, J. A. Rafols, Q. Lai, J. P. McAllister, II, and Y. Ding, 2005, Increased astrocyte proliferation in rats after running exercise: Neuroscience Letters, v. 386, p. 160-164. 
Liebelt, B. et al., 2010, Exercise preconditioning reduces neuronal apoptosis in stroke by upregulating heat shock protein-70 (heat shock protein-72) and extracellular-signalregulated-kinase 1/2: Neuroscience, v. 166, no. 4, p. 1091-1100.

Liu, J., I. Ginis, M. Spatz, and J. M. Hallenbeck, 2000, Hypoxic preconditioning protects cultured neurons against hypoxic stress via TNF-alpha and ceramide: Am J Physiol Cell Physiol, v. 278, no. 1, p. C144-C153.

Lloyd, P. G., B. M. Prior, H. Li, H. T. Yang, and R. L. Terjung, 2005, VEGF receptor antagonism blocks arteriogenesis, but only partially inhibits angiogenesis, in skeletal muscle of exercise-trained rats: Am.J.Physiol Heart Circ.Physiol, v. 288, no. 2, p. H759-H768.

Lloyd, P. G., B. M. Prior, H. T. Yang, and R. L. Terjung, 2003, Angiogenic growth factor expression in rat skeletal muscle in response to exercise training: Am J Physiol Heart Circ.Physiol, v. 284, no. 5, p. H1668-H1678.

Lloyd-Jones, D. et al., 2010, Heart disease and stroke statistics--2010 update: a report from the American Heart Association: Circulation, v. 121, no. 7, p. e46-e215.

Lo, E. H., T. Dalkara, and M. A. Moskowitz, 2003, Mechanisms, challenges and opportunities in stroke: Nat Rev Neurosci, v. 4, no. 5, p. 399-415.

Lo, E. H., M. A. Moskowitz, and T. P. Jacobs, 2005, Exciting, radical, suicidal: how brain cells die after stroke: Stroke, v. 36, no. 2, p. 189-192.

Masada, T., Y. Hua, G. Xi, S. R. Ennis, and R. F. Keep, 2001, Attenuation of ischemic brain edema and cerebrovascular injury after ischemic preconditioning in the rat: J Cereb Blood Flow Metab, v. 21, no. 1, p. 22-33.

Matsumori, Y. et al., 2005, Hsp70 overexpression sequesters AIF and reduces neonatal hypoxic/ischemic brain injury: J Cereb.Blood Flow Metab, v. 25, no. 7, p. 899910.

Maurer, M. H., H. K. Geomor, H. F. Burgers, D. W. Schelshorn, and W. Kuschinsky, 2006, Adult neural stem cells express glucose transporters GLUT1 and GLUT3 and regulate GLUT3 expression: FEBS Lett., v. 580, no. 18, p. 4430-4434.

Mayer, B., and R. Oberbauer, 2003, Mitochondrial regulation of apoptosis: News Physiol Sci., v. 18, p. 89-94.

McCloskey, D. P., D. S. Adamo, and B. J. Anderson, 2001, Exercise increases metabolic capacity in the motor cortex and striatum, but not in the hippocampus: Brain Res, v. 891, no. 1-2, p. 168-175.

McFarlin, B. K., M. G. Flynn, W. W. Campbell, B. A. Craig, J. P. Robinson, L. K. Stewart, K. L. Timmerman, and P. M. Coen, 2006, Physical activity status, but not age, influences inflammatory biomarkers and toll-like receptor 4: J.Gerontol.A Biol.Sci.Med.Sci., v. 61, no. 4, p. 388-393.

McGee, S. L., and M. Hargreaves, 2006, Exercise and skeletal muscle glucose transporter 4 expression: molecular mechanisms: Clin.Exp.Pharmacol.Physiol, v. 33, no. 4, p. 395399.

Minchenko, O., I. Opentanova, and J. Caro, 2003, Hypoxic regulation of the 6phosphofructo-2-kinase/fructose-2,6-bisphosphatase gene family (PFKFB-1-4) expression in vivo: FEBS Lett., v. 554, no. 3, p. 264-270.

Mori, E., G. J. del Zoppo, J. D. Chambers, B. R. Copeland, and K. E. Arfors, 1992, Inhibition of polymorphonuclear leukocyte adherence suppresses no-reflow after focal cerebral ischemia in baboons: Stroke, v. 23, no. 5, p. 712-718. 
Nawashiro, H., D. Martin, and J. M. Hallenbeck, 1997, Inhibition of tumor necrosis factor and amelioration of brain infarction in mice: J Cereb Blood Flow Metab, v. 17, no. 2, p. 229-232.

Neeper, S. A., P. Gomez, J. Choi, and C. W. Cotman, 1996, Physical activity increases mRNA for brain-derived neurotrophic factor and nerve growth factor in rat brain: Brain Res, v. 726, no. 1-2, p. 49-56.

Neurath, K. M., M. P. Keough, T. Mikkelsen, and K. P. Claffey, 2006, AMP-dependent protein kinase alpha 2 isoform promotes hypoxia-induced VEGF expression in human glioblastoma: Glia, v. 53, no. 7, p. 733-743.

Nishigaya, K., Y. Yoshida, M. Sasuga, H. Nukui, and G. Ooneda, 1991, Effect of recirculation on exacerbation of ischemic vascular lesions in rat brain: Stroke, v. 22, no. 5, p. 635642.

Noble, E. G., A. Moraska, R. S. Mazzeo, D. A. Roth, M. C. Olsson, R. L. Moore, and M. Fleshner, 1999, Differential expression of stress proteins in rat myocardium after free wheel or treadmill run training: J.Appl.Physiol, v. 86, no. 5, p. 16961701.

Ogoh, S., and P. N. Ainslie, 2009, Cerebral blood flow during exercise: mechanisms of regulation: J.Appl.Physiol, v. 107, no. 5, p. 1370-1380.

Ogunshola, O. O., W. B. Stewart, V. Mihalcik, T. Solli, J. A. Madri, and L. R. Ment, 2000, Neuronal VEGF expression correlates with angiogenesis in postnatal developing rat brain: Brain Res Dev Brain Res, v. 119, no. 1, p. 139-153.

Ohtsuka, K., and T. Suzuki, 2000, Roles of molecular chaperones in the nervous system: Brain Res Bull., v. 53, no. 2, p. 141-146.

Ostrakhovitch, E. A., and M. G. Cherian, 2005, Inhibition of extracellular signal regulated kinase (ERK) leads to apoptosis inducing factor (AIF) mediated apoptosis in epithelial breast cancer cells: the lack of effect of ERK in p53 mediated copper induced apoptosis: J Cell Biochem., v. 95, no. 6, p. 1120-1134.

Park, J. A., K. S. Choi, S. Y. Kim, and K. W. Kim, 2003, Coordinated interaction of the vascular and nervous systems: from molecule- to cell-based approaches: Biochem Biophys Res Commun, v. 311, no. 2, p. 247-253.

Petty, M. A., and E. H. Lo, 2002, Junctional complexes of the blood-brain barrier: permeability changes in neuroinflammation: Prog Neurobiol, v. 68, no. 5, p. 311323.

Petty, M. A., and J. G. Wettstein, 2001, Elements of cerebral microvascular ischaemia: Brain Res Brain Res Rev, v. 36, no. 1, p. 23-34.

Powers, S. K., S. L. Lennon, J. Quindry, and J. L. Mehta, 2002, Exercise and cardioprotection: Curr.Opin.Cardiol., v. 17, no. 5, p. 495-502.

Reyes, R., Jr., Y. Wu, Q. Lai, M. Mrizek, J. Berger, D. F. Jimenez, C. M. Barone, and Y. Ding, 2006, Early inflammatory response in rat brain after peripheral thermal injury: Neuroscience Letters, v. 407, no. 1, p. 11-15.

Romanic, A. M., R. F. White, A. J. Arleth, E. H. Ohlstein, and F. C. Barone, 1998, Matrix metalloproteinase expression increases after cerebral focal ischemia in rats: inhibition of matrix metalloproteinase-9 reduces infarct size: Stroke, v. 29, no. 5, p. 1020-1030. 
Rybnikova, E., N. Sitnik, T. Gluschenko, E. Tjulkova, and M. O. Samoilov, 2006, The preconditioning modified neuronal expression of apoptosis-related proteins of Bcl2 superfamily following severe hypobaric hypoxia in rats: Brain Res, v. 1089, no. 1, p. 195-202.

Sairanen, T. R., P. J. Lindsberg, M. Brenner, O. Carpen, and A. Siren, 2001, Differential cellular expression of tumor necrosis factor-alpha and Type I tumor necrosis factor receptor after transient global forebrain ischemia: J Neurol Sci, v. 186, no. 1-2, p. 8799.

Sawatzky, D. A., D. A. Willoughby, P. R. Colville-Nash, and A. G. Rossi, 2006, The involvement of the apoptosis-modulating proteins ERK 1/2, Bcl-xL and Bax in the resolution of acute inflammation in vivo: Am J Pathol., v. 168, no. 1, p. 3341.

Schabitz, W. R., T. Steigleder, C. M. Cooper-Kuhn, S. Schwab, C. Sommer, A. Schneider, and H. G. Kuhn, 2007, Intravenous brain-derived neurotrophic factor enhances poststroke sensorimotor recovery and stimulates neurogenesis: Stroke, v. 38, no. 7, p. 2165-2172.

Schlesinger, M. J., 1990, Heat shock proteins: J Biol Chem., v. 265, no. 21, p. 12111-12114.

Schubert, D., 2005, Glucose metabolism and Alzheimer's disease: Ageing Res.Rev., v. 4, no. 2, p. 240-257.

Semenza, G. L., 2009, Regulation of oxygen homeostasis by hypoxia-inducible factor 1: Physiology.(Bethesda.), v. 24, p. 97-106.

Shackelford, D. A., and R. Y. Yeh, 2006, Modulation of ERK and JNK activity by transient forebrain ischemia in rats: J Neurosci.Res, v. 83, no. 3, p. 476-488.

Shamloo, M., and T. Wieloch, 1999, Changes in protein tyrosine phosphorylation in the rat brain after cerebral ischemia in a model of ischemic tolerance: J.Cereb.Blood Flow Metab, v. 19, no. 2, p. 173-183.

Sharony, R., G. Pintucci, P. C. Saunders, E. A. Grossi, F. G. Baumann, A. C. Galloway, and P. Mignatti, 2005, Matrix Metalloproteinase Expression in Vein Grafts: Role of Inflammatory Mediators and Extracellular Signal-Regulated Kinases-1 and -2 2: Am.J Physiol Heart Circ.Physiol.

Siu, P. M., R. W. Bryner, J. K. Martyn, and S. E. Alway, 2004, Apoptotic adaptations from exercise training in skeletal and cardiac muscles: FASEB J., v. 18, no. 10, p. 11501152.

Stummer, W., K. Weber, B. Tranmer, A. Baethmann, and O. Kempski, 1994, Reduced mortality and brain damage after locomotor activity in gerbil forebrain ischemia: Stroke, v. 25, no. 9, p. 1862-1869.

Susin, S. A. et al., 1999, Molecular characterization of mitochondrial apoptosis-inducing factor: Nature, v. 397, no. 6718, p. 441-446.

Swain, R. A. et al., 2003, Prolonged exercise induces angiogenesis and increases cerebral blood volume in primary motor cortex of the rat: Neuroscience, v. 117, no. 4, p. 1037-1046.

Tagaya, M. et al., 2001, Rapid loss of microvascular integrin expression during focal brain ischemia reflects neuron injury: J Cereb Blood Flow Metab, v. 21, no. 7, p. 835-846.

Tawil, N. J., P. Wilson, and S. Carbonetto, 1994, Expression and distribution of functional integrins in rat CNS glia: J.Neurosci.Res., v. 39, no. 4, p. 436-447. 
Tong, L., D. Smyth, C. Kerr, J. Catterall, and C. D. Richards, 2004, Mitogen-activated protein kinases Erk1/2 and p38 are required for maximal regulation of TIMP-1 by oncostatin M in murine fibroblasts: Cell Signal., v. 16, no. 10, p. 1123-1132.

Vissing, J., M. Andersen, and N. H. Diemer, 1996, Exercise-induced changes in local cerebral glucose utilization in the rat: J Cereb Blood Flow Metab, v. 16, no. 4, p. 729-736.

Wagner, S., M. Tagaya, J. A. Koziol, V. Quaranta, and G. J. del Zoppo, 1997, Rapid disruption of an astrocyte interaction with the extracellular matrix mediated by integrin alpha 6 beta 4 during focal cerebral ischemia/reperfusion: Stroke, v. 28, no. 4, p. 858-865.

Wang, R. Y., Y. R. Yang, and S. M. Yu, 2001, Protective effects of treadmill training on infarction in rats: Brain Res, v. 922, no. 1, p. 140-143.

Wang, X., X. Li, J. A. Erhardt, F. C. Barone, and G. Z. Feuerstein, 2000, Detection of tumor necrosis factor-alpha mRNA induction in ischemic brain tolerance by means of real-time polymerase chain reaction: J Cereb Blood Flow Metab, v. 20, no. 1, p. 1520.

Williamson, J. W., A. C. Nobrega, R. McColl, D. Mathews, P. Winchester, L. Friberg, and J. H. Mitchell, 1997, Activation of the insular cortex during dynamic exercise in humans: J Physiol, v. 503 ( Pt 2), p. 277-283.

Willis, C. L., C. C. Nolan, S. N. Reith, T. Lister, M. J. Prior, C. J. Guerin, G. Mavroudis, and D. E. Ray, 2004, Focal astrocyte loss is followed by microvascular damage, with subsequent repair of the blood-brain barrier in the apparent absence of direct astrocytic contact: Glia, v. 45, no. 4, p. 325-337.

Wu, C., H. Fujihara, J. Yao, S. Qi, H. Li, K. Shimoji, and H. Baba, 2003, Different expression patterns of Bcl-2, Bcl-xl, and Bax proteins after sublethal forebrain ischemia in C57Black/Crj6 mouse striatum: Stroke, v. 34, no. 7, p. 1803-1808.

Yamashita, N., S. Hoshida, K. Otsu, N. Taniguchi, T. Kuzuya, and M. Hori, 1999, Monophosphoryl lipid A provides biphasic cardioprotection against ischaemiareperfusion injury in rat hearts: Br J Pharmacol, v. 128, no. 2, p. 412-418.

Yang, G. Y., and A. L. Betz, 1994, Reperfusion-induced injury to the blood-brain barrier after middle cerebral artery occlusion in rats: Stroke, v. 25, no. 8, p. 1658-1664.

Yong, V. W., C. Power, P. Forsyth, and D. R. Edwards, 2001, Metalloproteinases in biology and pathology of the nervous system: Nat Rev Neurosci, v. 2, no. 7, p. 502511.

Zhu, C., L. Qiu, X. Wang, U. Hallin, C. Cande, G. Kroemer, H. Hagberg, and K. Blomgren, 2003, Involvement of apoptosis-inducing factor in neuronal death after hypoxiaischemia in the neonatal rat brain: J Neurochem., v. 86, no. 2, p. 306-317.

Zhuang, S., and R. G. Schnellmann, 2006, A death-promoting role for extracellular signalregulated kinase: J Pharmacol.Exp.Ther., v. 319, no. 3, p. 991-997.

Zorzano, A., M. Palacin, and A. Guma, 2005, Mechanisms regulating GLUT4 glucose transporter expression and glucose transport in skeletal muscle: Acta Physiol Scand., v. 183, no. 1, p. 43-58.

Zwagerman, N., C. Plumlee, M. Guthikonda, and Y. Ding, 2010a, Toll-like receptor-4 and cytokine cascade in stroke after exercise: Neurological Research, v. 32, no. 2, p. 123126. 
Zwagerman, N., S. Sprague, M. D. Davis, B. Daniels, G. Goel, and Y. Ding, 2010b, Preischemic exercise preserves cerebral blood flow during reperfusion in stroke: Neurological Research. 


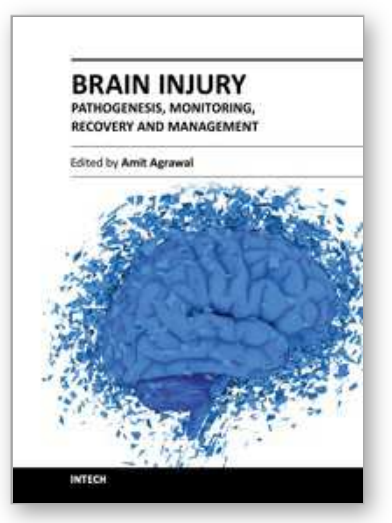

\author{
Brain Injury - Pathogenesis, Monitoring, Recovery and \\ Management \\ Edited by Prof. Amit Agrawal
}

ISBN 978-953-51-0265-6

Hard cover, 522 pages

Publisher InTech

Published online 23, March, 2012

Published in print edition March, 2012

The present two volume book "Brain Injury" is distinctive in its presentation and includes a wealth of updated information on many aspects in the field of brain injury. The Book is devoted to the pathogenesis of brain injury, concepts in cerebral blood flow and metabolism, investigative approaches and monitoring of brain injured, different protective mechanisms and recovery and management approach to these individuals, functional and endocrine aspects of brain injuries, approaches to rehabilitation of brain injured and preventive aspects of traumatic brain injuries. The collective contribution from experts in brain injury research area would be successfully conveyed to the readers and readers will find this book to be a valuable guide to further develop their understanding about brain injury.

\title{
How to reference
}

In order to correctly reference this scholarly work, feel free to copy and paste the following:

David Dornbos III and Yuchuan Ding (2012). Mechanisms of Neuroprotection Underlying Physical Exercise in Ischemia - Reperfusion Injury, Brain Injury - Pathogenesis, Monitoring, Recovery and Management, Prof. Amit Agrawal (Ed.), ISBN: 978-953-51-0265-6, InTech, Available from: http://www.intechopen.com/books/braininjury-pathogenesis-monitoring-recovery-and-management/mechanisms-of-neuroprotection-underlyingphysical-exercise-in-ischemia-reperfusion-injury

\section{INTECH}

open science | open minds

\author{
InTech Europe \\ University Campus STeP Ri \\ Slavka Krautzeka 83/A \\ 51000 Rijeka, Croatia \\ Phone: +385 (51) 770447 \\ Fax: +385 (51) 686166 \\ www.intechopen.com
}

\author{
InTech China \\ Unit 405, Office Block, Hotel Equatorial Shanghai \\ No.65, Yan An Road (West), Shanghai, 200040, China \\ 中国上海市延安西路65号上海国际贵都大饭店办公楼 405 单元 \\ Phone: +86-21-62489820 \\ Fax: +86-21-62489821
}


(C) 2012 The Author(s). Licensee IntechOpen. This is an open access article distributed under the terms of the Creative Commons Attribution 3.0 License, which permits unrestricted use, distribution, and reproduction in any medium, provided the original work is properly cited. 